УДК 332.133 .2

DOI 10.18413/2687-0932-2020-47-2-244-253

\title{
ДИАГНОСТИКА КОНКУРЕНТОСПОСОБНОСТИ РЕГИОНА В КОНТЕКСТЕ ПРИВЛЕЧЕНИЯ ЧЕЛОВЕЧЕСКОГО КАПИТАЛА
}

\section{DIAGNOSTICS OF REGIONAL COMPETITIVENESS IN THE CONTEXT OF ATTRACTING HUMAN CAPITAL}

\author{
А.С. Глотова ${ }^{1}$, Д.С. Глотов ${ }^{2}$, И.Н. Титова ${ }^{1}$ \\ A.S. Glotova, D.S. Glotov, I.N. Titova \\ ${ }^{1)}$ Белгородский государственный национальный исследовательский университет, \\ Россия, 308015, г. Белгород, ул. Победы, д. 85 \\ ${ }^{2)}$ Администрация Яковлевского городского округа, \\ Россия, 309070, Белгородская область, Яковлевский р-н, г. Строитель, ул. Ленина, д. 16 \\ ${ }^{1)}$ Belgorod State University, 85 Pobeda St, Belgorod, 308015, Russia \\ ${ }^{2)}$ Administration of Yakovlevsky City District, \\ 16 Lenin str., Stroitel, Yakovlevsky District, Belgorod region, 309070, Russia \\ E-mail: glotova@bsu.edu.ru,301709@mail.ru, titova@bsu.edu.ru
}

\begin{abstract}
Аннотация
На сегодняшний день конкурентоспособность региона должна быть ориентирована на учет и комплексность всех аспектов регионального роста, которые проявляются через призму человеческого развития. Конкурентоспособность региона выступает определяющим фактором привлечения и накопления человеческого капитала. Поэтому одним из приоритетных направлений пространственного развития территории является формирование конкурентной среды, которая способствует притоку человеческого капитала. Именно в данном контексте была проведена диагностика конкурентоспособности областей Центрально-Черноземного макрорегиона. На основе интегральной оценки были выявлены 3 группы регионов по уровню конкурентоспособности, а также определены факторы роста и ограничения привлечения человеческого капитала в регионы.
\end{abstract}

\begin{abstract}
Currently, the socio-economic development of the region is impossible without interregional competition. The universal criterion for evaluating the functioning of the territory has become competitiveness, which is a priority factor of socio-economic development. It is the region's competitiveness that largely determines its role and place in the country's economic space. In the context of globalization processes, it is increasingly clear that the most important economic factor in society is not material and financial resources, but human capital. Human capital determines the competitive advantages of the regional economy and the opportunities for its modernization. Therefore, one of the priority directions of spatial development of the territory is the formation of conditions conducive to attracting and accumulating human capital. It was in this context that the diagnostics of the competitiveness of the regions of the Central Chernozem macro-region was carried out. Based on the integrated assessment, 3 groups of regions were identified by the level of competitiveness. We also identified growth factors and restrictions on attracting human capital to the regions.
\end{abstract}

Ключевые слова: конкурентоспособность, человеческий капитал, регион, интегральная оценка. Keywords: competitiveness, human capital, region, integrated assessment.

\section{Введение}

Глобализация отводит регионам качественно новую роль в экономике, выдвигая перед ними новые задачи по содержанию как можно более высоких показателей конкурентоспособности в национальном и международном измерениях. Регионы становятся 
равноправными субъектами экономических отношений, порождающих соответствующую конкурентную борьбу между ними. Человеческий капитал является незаменимым фактором, обеспечивающим конкурентоспособность экономических субъектов. С одной стороны, конкурентоспособность региона определяется качеством населения (человеческого потенциала). С другой стороны, именно формирование и развитие человеческого капитала обуславливает уровень конкурентоспособности экономического субъекта. Неравномерное пространственное распределение человеческого капитала в основном вызвано диспропорциями в создании конкурентных преимуществ регионального развития. Снижение уровня конкурентоспособности территории всегда сопряжено с оттоком человеческого капитала из регионов, что в свою очередь препятствует их устойчивому развитию. В российских регионах наблюдается высокий уровень дифференциации по плотности человеческого капитала, значительно превышающий дифференциацию по его абсолютной величине. Что в свою очередь означает недоиспользование экономического пространства, которым располагают регионы. Исследование уровня конкурентоспособности в разрезе определяющих его факторов позволяет оценить объективные условия развития человеческого потенциала в регионах на основе ретроспективного анализа статистических данных.

\section{Методика исследования}

В основе большинства методик, описанных различными авторами [Клюев, 2012; Гагарина, 2012; Квасов, Левина, 2015; Симанавичене и др., 2013], лежит оценка влияния человеческого капитала, на конкурентоспособность региона. Так, по мнению И.А. Филлиповой, перспективы конкурентоспособности региона находятся в полной зависимости от состояния человеческого потенциала [Филлипова, 2011]. Подтверждает также наличие прямой взаимосвязи человеческого капитала и экономического развития региона и исследование, опубликованное в Докладе о развитии человеческого потенциала в РФ [Бобылев, 2018].

Наше исследование нацелено на изучение влияния уровня конкурентоспособности территории на привлечение и накопление человеческого капитала.

На наш взгляд, предлагаемая количественная оценка региональной конкурентоспособности сквозь призму человеческого потенциала может послужить основой для разработки стратегии региона по привлечению и накоплению человеческого капитала.

Конкурентоспособность региона невозможно охарактеризовать одним частным индикатором. Для всесторонней оценки конкурентоспособности региона наиболее целесообразно использование индикативного метода анализа [Глотова, Титова, Лыщикова, 2018]. Суть данного метода состоит в сопоставлении ряда индикаторов, которые позволяют получить количественную и качественную характеристику исследуемого объекта. При этом важно учитывать количественный и структурный состав используемых показателей, имеющих существенные отличия. В настоящее время нет единой концепции реализации данного метода по причине неоднозначности последовательности расположения используемых показателей, а также их взаимосвязи.

Несмотря на существующие различия в концептуальных подходах к исследованию конкурентоспособности регионов и его оценки на основе индикативного метода анализа, предлагаем включить в данный процесс последовательную реализацию следующих этапов (рис. 1).

Первостепенной проблемой при разработке методологии, на наш взгляд, выступает отбор индикаторов, которые будут включены в интегральную оценку конкурентоспособности региона.

Учитывая, что система индикаторов оценки конкурентоспособности региона выполняет одновременно несколько функций, следовательно качество отобранных показателей будет обеспечивать эффективность управленческих решений в данном контексте. Этот перечень не должен быть слишком большим, поскольку это усложнит выявление действительно важных факторов. 


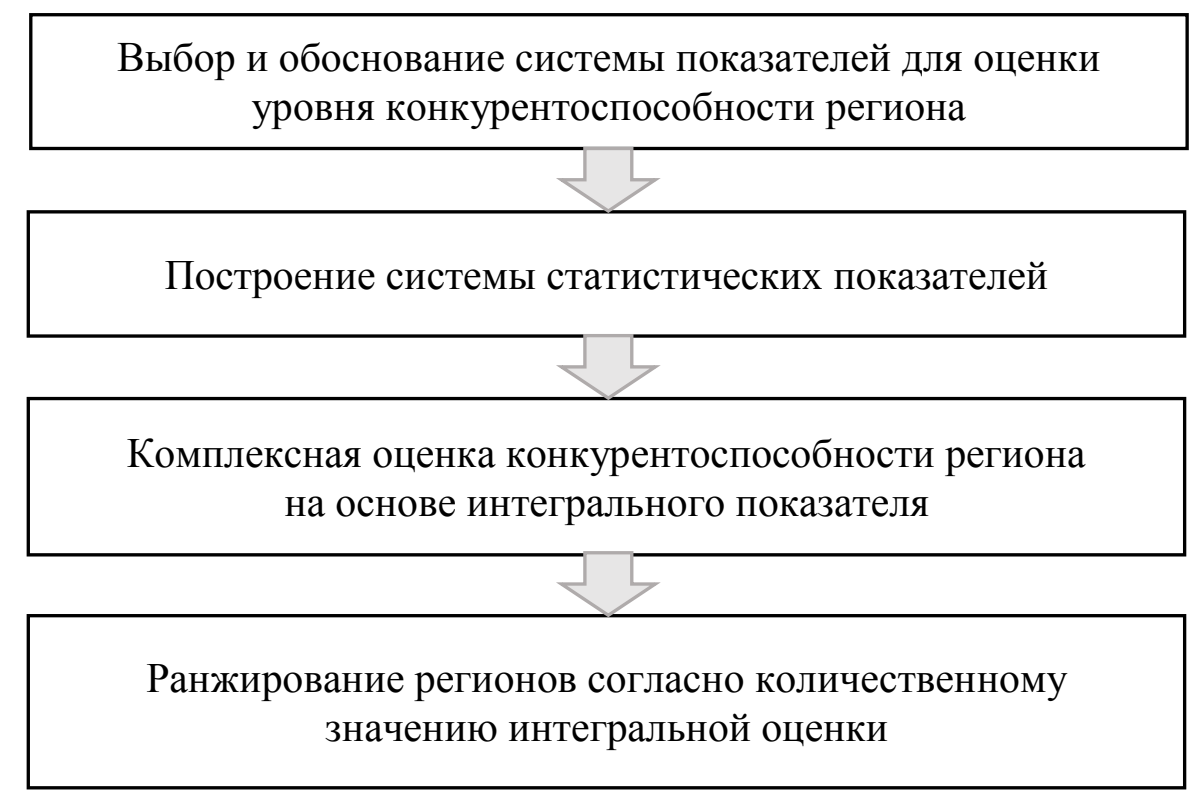

Рис. 1. Основные этапы исследования конкурентоспособности региона

Fig. 1. Main stages of regional competitiveness research

С одной стороны, большое количество показателей способствует повышению качеств информационной модели, а с другой - приводит к информационной перегрузке процессов принятия решений и делает трудной интерпретацию полученных результатов, поэтому целесообразным при формировании системы показателей будет учет определенных требований:

- система показателей должна обеспечить максимальную информативность результатов оценки;

- в перечень показателей целесообразно включать только значимые для оценки конкурентоспособности региона показатели;

- система показателей должна быть полной и обеспечивать достаточную интенсивность измерения, то есть показатели должны образовывать взаимосвязанные системы, имеющие большую внутреннюю изменчивость;

- система показателей должна быть достоверной, адекватно отражать реальное состояние региональных систем, быть нейтральной по отношению к другим объектам оценки;

- система показателей должна обеспечивать возможность проведения сравнительного (фонового) анализа конкурентоспособности региона во времени;

- система показателей должна быть информационно прозрачной.

Анализ научных трудов, в которых исследуются методики оценки региональной конкурентоспособности [Ахунов, 2016; Батрак, 2016; Меркушов, 2004; Ушвицкий, Парахина, 2005; Ларина, Макаев, 2006; Шеховцева, 2007] позволил выявить набор необходимых показателей, которые были объединены в восемь групп факторов (рис. 2).

В ходе проведения анализа, отобранные индикаторы проходят процесс нормирования. Обычно в качестве нормативных значений предлагается использовать пороговые или предельно-критические значения. Сопоставляя фактические региональные показатели с критическими значениями, можно определить, в какой степени территориальные показатели соответствуют нормативам, принятыми в мировой практике.

Используемые в анализе показатели, оказывающие влияние на уровень конкурентоспособности региона, рационально разделить на показатели-стимуляторы и показатели-дестимуляторы.

К показателям-стимуляторам относятся те из них, которые способствуют улучшению ситуации в регионе и тем самым повышают уровень конкурентоспособности. 


\section{ИНТЕГРАЛЬНЫЙ ИНДЕКС КОНКУРЕНТОСПОСОБНОСТИ РЕГИОНА}

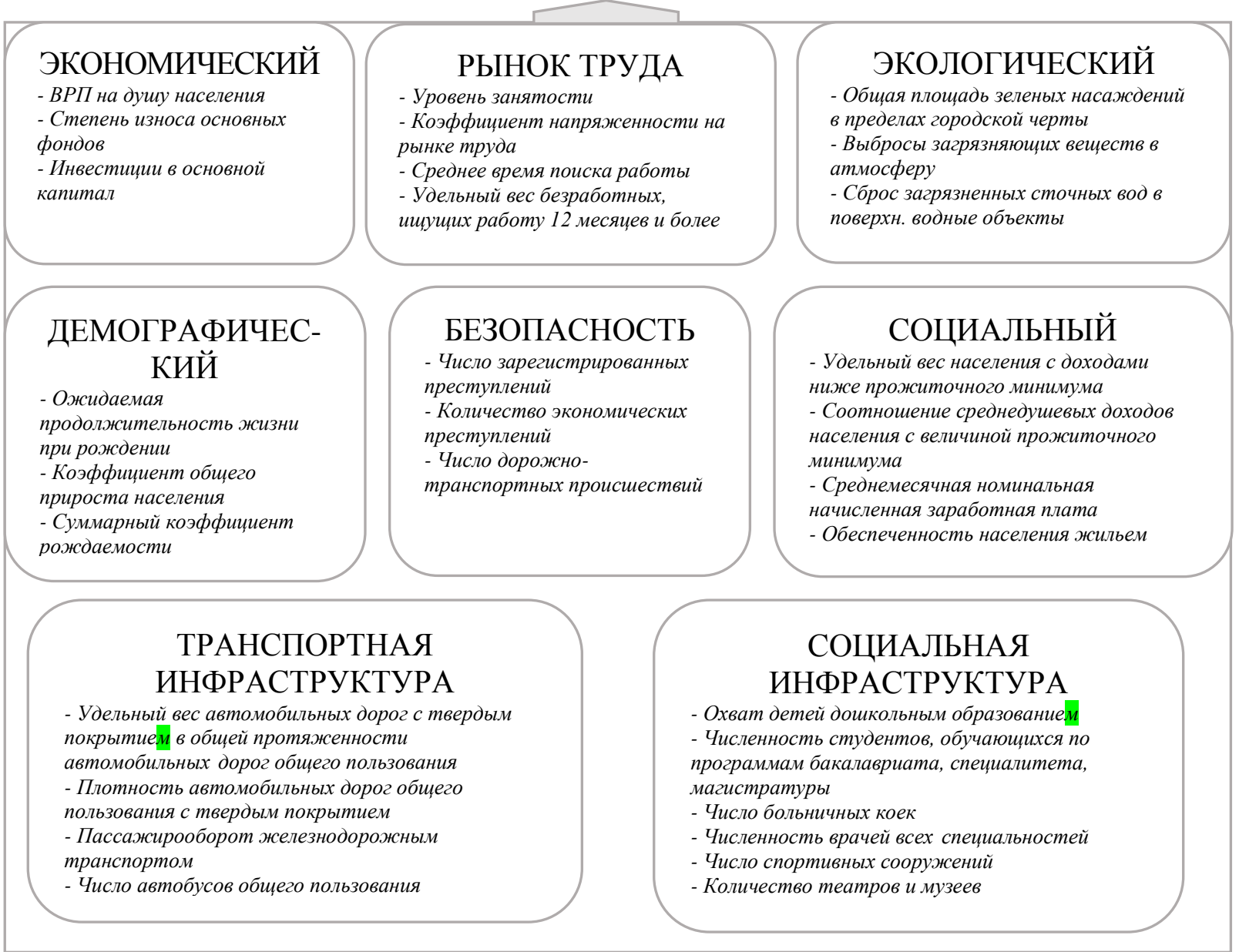

Рис. 2. Структура индекса конкурентоспособности региона в контексте привлечения человеческого капитала

Fig. 2. Structure of the regional competitiveness index in the context of attracting human capital

Дестимуляторами являются показатели, имеющие противоположную направленность в отношении влияния на социально-экономическое развитие региона и приводят к возникновению рисков и угроз конкурентоспособности региона.

Нормирование показателей будет произведено с использованием метода «минимуммаксимум». Основным преимуществом применения данного метода является то, что он позволяет избежать чрезмерного влияния какого-либо одного показателя на интегральную оценку.

Показатели-стимуляторы нормируются по формуле:

$$
X_{i}=\frac{X-X_{\min }}{X_{\max }-X_{\min }} .
$$

В случае показателя-дестимулятора используется следующая формула:

$$
X_{i}=1-\frac{X-X_{\min }}{X_{\max }-X_{\min }}
$$

где $\mathrm{X}$ - фактическое значение рассматриваемого показателя;

$X_{\max }$ - наибольшее значение рассматриваемого показателя;

$X_{\min }$ - наименьшее значение рассматриваемого показателя.

В соответствии с предложенной методикой, частные индикаторы рассчитываются в разрезе отдельных групп факторов. Сводный интегральный индикатор определяется на основе частных индикаторов и отражает уровень конкурентоспособности территории. 
Частные индикаторы рассчитываются по формуле:

$$
I_{i}=\sum_{i=1}^{n} d_{i} \cdot x_{i},
$$

где $\mathrm{n}$ - количество статистических показателей в і-том частном индикаторе;

$\mathrm{d}_{\mathrm{i}}-$ весовой коэффициент, который рассчитывается по формуле:

$$
d_{i}=\frac{\rho_{i}}{\sum_{i=1}^{m} \rho_{i}},
$$

где m - число показателей;

$\rho_{\mathrm{i}}-$ коэффициент относительного разброса

$$
\rho_{i}=\frac{x_{\max }-x_{\min }}{x_{\max }} .
$$

Комплексная оценка состояния конкурентоспособности региона осуществляется на основе сводного интегрального показателя:

$$
I_{\text {инт }}=\sum_{i=1}^{k} \bar{d}_{i} \cdot I_{i},
$$

где $\mathrm{k}$ - число частных индикаторов;

$\bar{d}-$ весовой коэффициент частного индикатора.

Достоинство формулы (6) состоит в том, что она позволяет учитывать долю влияния каждого частного индикатора на интегральный показатель.

В методике выявлено пять уровней значений частных и интегральных индикаторов, значения которых варьируются в пределах от 0 до 1. Градация значений индикаторов конкурентоспособности региона представлена в таблице 1.

Таблица 1

Table 1

Пороговые значения индикаторов конкурентоспособности региона

Threshold values of regional competitiveness indicators

\begin{tabular}{|c|c|}
\hline $\begin{array}{c}\text { Границы интервала } \\
\text { индекса }\end{array}$ & $\begin{array}{c}\text { Уровень } \\
\text { конкурентоспособности региона }\end{array}$ \\
\hline $0,8<\mathrm{I}<1,0$ & Высокий \\
\hline $0,6<\mathrm{I}<0,8$ & Выше среднего \\
\hline $0,4<\mathrm{I}<0,6$ & Средний \\
\hline $0,2<\mathrm{I}<0,4$ & Низкий \\
\hline $0,0<\mathrm{I}<0,2$ & Очень низкий \\
\hline
\end{tabular}

\section{Результаты исследования и обсуждение}

Данная методика была использована для оценки уровня конкурентоспособности регионов в контексте привлечения человеческого капитала.

Основные параметры исследования:

- в исследовании участвуют области Центрально-Черноземного макрорегиона: Белгородская, Воронежская, Курская, Липецкая, Тамбовская;

- системное исследование конкурентоспособности проводилось в рамках временного промежутка с 2016 по 2018 гг.;

- в исследовании используются статистические данные (показатели);

- каждый показатель был нормирован согласно вышеописанной методике;

- были рассчитаны частные и сводные индикаторы;

- согласно градации, каждому индикатору был присвоен уровень конкурентоспособности.

Индекс конкурентоспособности региона в контексте привлечения человеческого капитала - комплексная оценка, характеризующая фактическую способность территории конкурировать за человеческие ресурсы. 
Индекс конкурентоспособности региона отражает фактическую реализацию факторов конкуренции, т. е. оценивает индикаторы, отражающие результаты межрегиональной конкуренции.

В качестве источника для формирования индекса конкурентоспособности служат статистические показатели и результаты публичных исследований регионов.

Результаты расчетов сводного индикатора конкурентоспособности регионов представлены на рисунке 3.

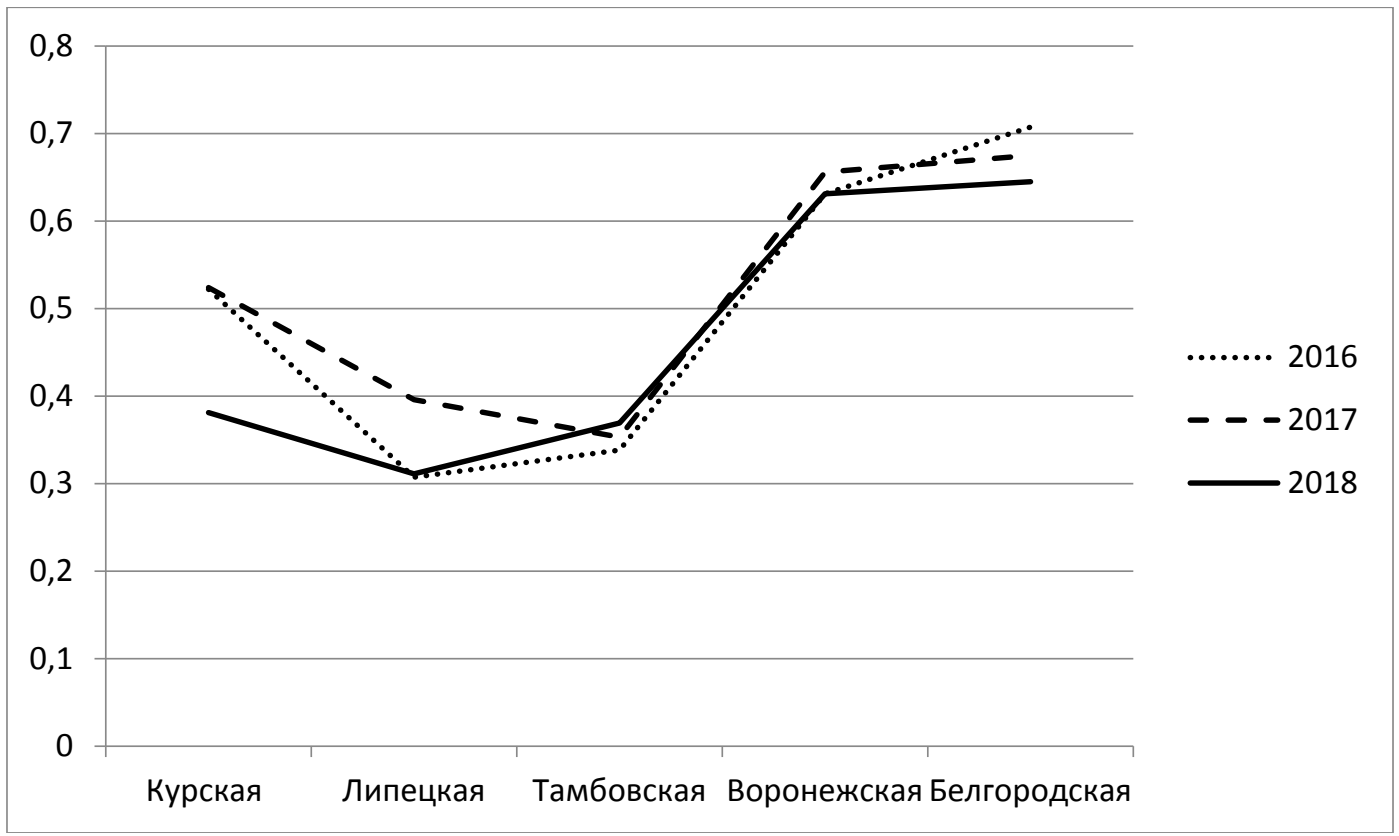

Рис. 3. Динамика интегрального индекса уровня конкурентоспособности областей Центрально-Черноземного макрорегиона

Fig. 3. Dynamics of the integral index of the level of competitiveness of the regions of the Central Chernozem macroregion

В настоящем исследовании было выделено несколько групп регионов по уровню конкурентоспособности:

- Группа 1. Регионы-лидеры со значением интегрального показателя более 0,8. Регионы, образующие центры полюсов роста, являющиеся ключевыми драйверами развития экономики макрорегиона и страны. В Центрально-Черноземном макрорегионе таких регионов выявлено не было.

- Группа 2. Регионы со значением интегрального показателя от 0,6 до 0,8 - обладают потенциалом перехода в число «регионов-лидеров» полюсов роста, и оказывают существенное влияние на развитие полюсов. В число таких регионов входят: Белгородская и Воронежская области.

- Группа 3. Регионы со значением интегрального показателя менее 0,6. Согласно оценке, к таким регионам относится Курская, Липецкая и Тамбовская области.

Распределение областей по группам в зависимости от уровня конкурентоспособности обеспечивает соответствующий уровню показатель механического прироста численности населения (рисунок 4).

Как видно из рисунка 4, Белгородская и Воронежская области, имеющие «выше среднего» уровень конкурентоспособности, характеризуются положительным миграционным приростом, что доказывает обоснованность основных положений исследования. Регионы группы 3 имеют отрицательный миграционный прирост и, следовательно, низкий приток человеческого капитала. 


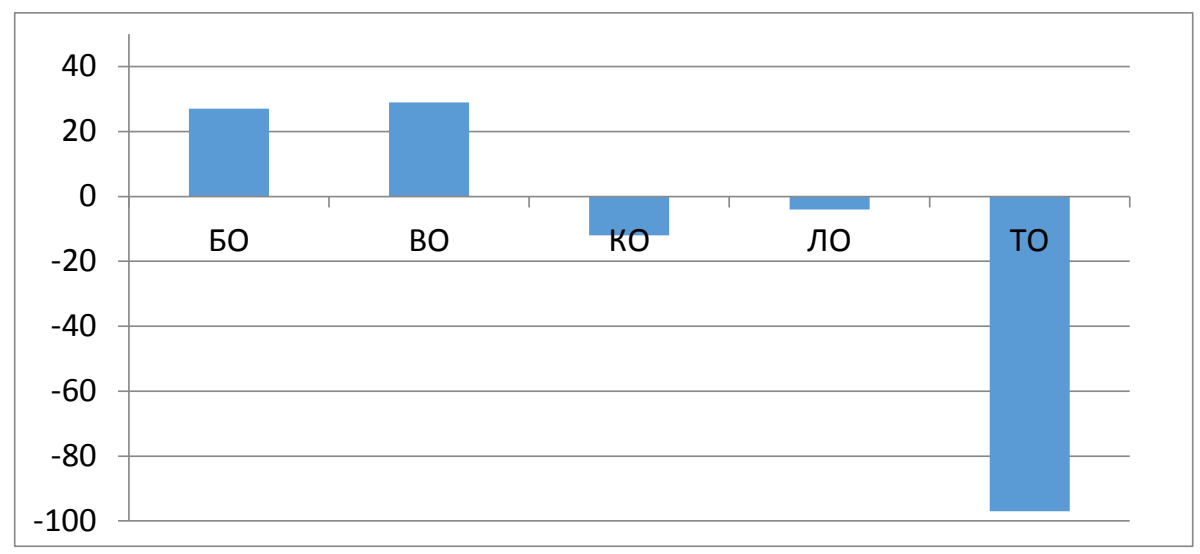

Рис. 4. Миграционный прирост численности населения областей Центрально-Черноземного макрорегиона

Fig. 4. Migration growth of the population of the regions of the Central Chernozem macroregion

На втором этапе анализа была проведена оценка уровня конкурентоспособности региона по отдельным факторам с учетом значений частных индикаторов (таблица 2).

Таблица 2

Table 2

Матрица распределения областей Центрально-Черноземного макрорегиона по уровню конкурентоспособности

The distribution matrix of regions of Central Chernozem macroregion according to the level of competitiveness

\begin{tabular}{|c|c|c|c|c|c|}
\hline & Высокий & $\begin{array}{c}\text { Выше } \\
\text { среднего }\end{array}$ & Средний & Низкий & $\begin{array}{c}\text { Очень } \\
\text { низкий }\end{array}$ \\
\hline $\begin{array}{l}\text { Экономический } \\
\text { фактор }\end{array}$ & & $\mathrm{BO}$ & $\begin{array}{l}\text { ЛО } \\
\text { ТО } \\
\text { БО }\end{array}$ & KO & \\
\hline $\begin{array}{l}\text { Социальный } \\
\text { фактор }\end{array}$ & & $\begin{array}{l}\text { ЛО } \\
\text { БО }\end{array}$ & $\begin{array}{l}\mathrm{KO} \\
\mathrm{BO}\end{array}$ & TO & \\
\hline $\begin{array}{l}\text { Демографический } \\
\text { фактор }\end{array}$ & $\mathrm{BO}$ & $\begin{array}{l}\text { КО } \\
\text { БО }\end{array}$ & ЛО & $\mathrm{TO}$ & \\
\hline Безопасность & БО & & $\begin{array}{l}\text { ЛО } \\
\text { ТО }\end{array}$ & $\begin{array}{l}\mathrm{KO} \\
\mathrm{BO}\end{array}$ & \\
\hline Рынок труда & БО & $\mathrm{BO}$ & ЛО & $\begin{array}{l}\mathrm{KO} \\
\mathrm{TO}\end{array}$ & \\
\hline $\begin{array}{l}\text { Экологический } \\
\text { фактор }\end{array}$ & КO & $\begin{array}{l}\mathrm{BO} \\
5 \mathrm{O}\end{array}$ & TO & & ЛО \\
\hline $\begin{array}{l}\text { Социальная } \\
\text { инфраструктура }\end{array}$ & & $\begin{array}{l}\mathrm{BO} \\
\text { БO }\end{array}$ & $\begin{array}{l}\mathrm{KO} \\
\mathrm{TO}\end{array}$ & ЛО & \\
\hline $\begin{array}{l}\text { Транспортная } \\
\text { инфраструктура }\end{array}$ & & & $\begin{array}{l}\mathrm{BO} \\
\mathrm{5O}\end{array}$ & $\mathrm{KO}$ & $\begin{array}{l}\text { ЛО } \\
\text { ТО }\end{array}$ \\
\hline
\end{tabular}

Данная матрица позволяет выделить конкурентные преимущества региона, а также определить факторы, которые ограничивают привлечение человеческого капитала в данные регионы.

На основании таблицы 2 были определены позиции регионов по уровню конкурентоспособности с учетом рассматриваемых факторов (рисунок 5). 


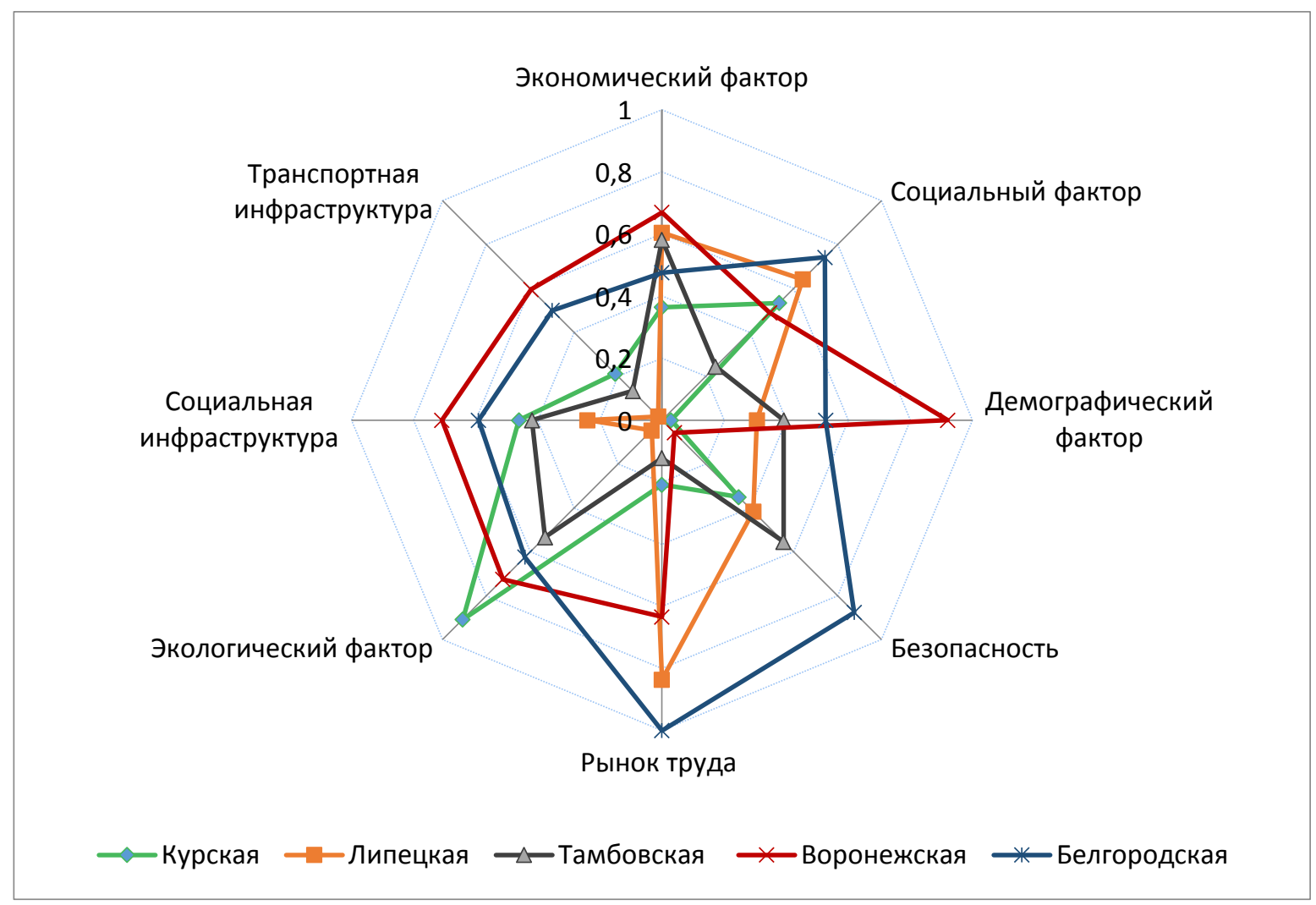

Рис. 5. Позиции областей Центрально-Черноземного макрорегиона по уровню конкурентоспособности с учетом факторов

Fig. 5. Positions of the regions of the Central Chernozem macro-region in terms of competitiveness, considering factors

\section{Заключение}

Результаты оценки на основе индикативного анализа позволяют определить место региона относительно других регионов, а также выявить лидеров и аутсайдеров по уровню конкурентоспособности с целью принятия дальнейших управленческих решений.

Итак, Белгородская и Воронежская области занимают лидирующие позиции по уровню конкурентоспособности регионов в контексте привлечения человеческого капитала. Высокую оценку конкурентоспособности Белгородская область получила по направлениям «Социальный фактор», «Безопасность» и «Рынок труда», Воронежская область по направлениям: «Демографический фактор», «Экономический фактор», «Транспортная и социальная инфраструктура». Сдерживающими факторами для данных регионов являются: для Белгородской «Экономический фактор», для Воронежской области «Безопасность».

Для регионов группы 3 ключевыми проблемами являются:

- Тамбовская область: «Транспортная инфраструктура», «Социальный фактор», «Демографический фактор», «Рынок труда»;

- Липецкая область: «Экологический фактор», «Социальная и транспортная инфраструктура»;

- Курская область: «Экономический фактор», «Транспортная инфраструктура», «Безопасность», «Рынок труда».

Таким образом, полученные результаты оценки конкурентоспособности региона могут быть использованы органами власти и управления территории при формировании стратегии привлечения человеческого капитала. При этом направление курса развития региона в данном контексте будет определено с учетом выявленных ускоряющих и сдерживающих факторов для каждой конкретной группы регионов. 


\section{Список литературы}

1. Ахунов Р.Р. 2016. Оценка конкурентоспособности региона на основе структурных элементов воспроизводственного потенциала. Региональная экономика: теория и практика, 2: 107-124.

2. Батрак В.С. 2016. Методика оценки уровня конкурентоспособности регионов. Региональная экономика: теория и практика, 4: 89-103.

3. Гагарина Г.Ю. 2012. Человеческий капитал и его роль в обеспечении конкурентоспособности российских регионов. Стратегия развития региона, 23 (254): 9-14.

4. Глотова А.С., Титова И.Н., Лыщикова Ю.В. 2018. Интегральная оценка демографической безопасности региона. Современная экономика: проблемы и решения, 5: 111-122.

5. Бобылев С.Н., Григорьев Л.М. 2018. Доклад о человеческом развитии в Российской Федерации за 2018 год. Аналитический центр при Правительстве Российской Федерации, 172.

6. Квасов И.А., Левина Н.В. 2015. Влияние человеческого капитала на конкурентоспособность социально-экономической системы. Интернет-журнал «Науковедение». Режим доступа: http://naukovedenie.ru/PDF/14EVN215.pdf

7. Клюев К.В. 2012. Человеческий капитал как основа конкурентоспособности Ленинградской области. Журнал правовых и экономических исследований, 3: 63-66.

8. Ларина Н.И., Макаев А.И. 2006. Кластеризация как путь повышения международной конкурентоспособности страны и регионов, 10: 2-26.

9. Меркушов В.В. 2004. Интегральная оценка конкурентоспособности регионов. Региональная наука: сб. науч. тр. молодых ученых, 288.

10.Симанавичене Ж., Гижене В., Хаджинов И.В. 2013. Влияние человеческого капитала на конкурентоспособность регионов, Theoretical and Practical Aspects of Economics and Intellectual Property, выпуск 1, Т. 1.: 211-215.

11.Филлипова И.А. 2011. Влияние развития региона на формирование человеческого капитала. Региональная экономика: теория и практика, 39(219): 9-15.

12.Ушвицкий Л.И., Парахина В.Н. 2005. Конкурентоспособность региона как новая реалия: сущность, методы оценки, современное состояние. Сборник научных трудов СевКавГТУ. Серия «Экономика», 1: 1-20.

13.Шеховцева Л.С. 2007. Интегральная оценка стратегической конкурентоспособности российских регионов. Вестник ИНЖЭКОНа, 4 (17):109-115.

14.Stryabkova E.A., Chistnikova I.V., Lyshchikova J.V., Dobrodomova T.N., Mochalova Ya.V., Izvarin A.A. 2018. Human capital as a strategic factor in the development of the regional economy. Revista Publicando, 15: 1492-1502. Mode of access: https://rmlconsultores.com/revista/index.php/crv/article/view/ 1468/pdf_1074

15.Stryabkova E.A., Glotova A.S., Titova I.N., Lyshchikova J.V., Chistnikova I.V. 2018. Modeling and forecasting of socio-economic development of the region. The Journal of Social Sciences Research, 5: 404-410. Mode of access: https://arpgweb.com/pdf-files/spi5.11.404.410.pdf

\section{References}

1. Ahunov R.R. 2016. Ocenka konkurentosposobnosti regiona na osnove strukturnyh elementov vosproizvodstvennogo potenciala [Assessment of regional competitiveness based on structural elements of reproductive potential]. Regional'naya ekonomika: teoriya i praktika, 2: 107-124.

2. Batrak V.S. 2016. Metodika ocenki urovnya konkurentosposobnosti regionov [Methodology for assessing the level of regional competitiveness]. Regional'naya ekonomika: teoriya i praktika, 4: 89-103.

3. Gagarina G.YU. 2012. CHelovecheskij kapital i ego rol' v obespechenii konkurentosposobnosti Rossijskih regionov [Human capital and its role in ensuring the competitiveness of Russian regions]. Strategiya razvitiya regiona, 23 (254): 9-14.

4. Glotova A.S., Titova I.N., Lyshchikova YU.V. 2018. Integral'naya ocenka demograficheskoj bezopasnosti regiona [Integrated assessment of the region's demographic security]. Sovremennaya ekonomika: problemy i resheniya, 5: 111-122.

5. Bobylev S.N., Grigor'ev L.M. 2018. Doklad o chelovecheskom razvitii v Rossiyskoy Federatsii za 2018 god. Analiticheskiy tsentr pri Pravitel'stve Rossiyskoy Federatsii, 172.

6. Kvasov I.A., Levina N.V. 2015. Vliyanie chelovecheskogo kapitala na konkurentosposobnost' sotsial'no-ekonomicheskoy sistemy. Internet-zhurnal «Naukovedenie». Available at: http://naukovedenie.ru/ PDF/14EVN215.pdf 
7. Klyuev K.V. 2012. CHelovecheskij kapital kak osnova konkurentosposobnosti Leningradskoj oblasti [Human capital as the basis of competitiveness]. ZHurnal pravovyh i ekonomicheskih issledovanij, 3: 63-66.

8. Larina N.I., Makaev A.I. 2006. Klasterizatsiya kak put' povysheniya mezhdunarodnoy konkurentosposobnosti strany i regionov, 10: 2-26.

9. Merkushov V.V. 2004. Integral'naya otsenka konkurentosposobnosti regionov. Regional'naya nauka: sb. nauch. tr. molodykh uchenykh, 288.

10.Simanavichene ZH., Gizhene V., Hadzhinov I.V. 2013. Vliyanie chelovecheskogo kapitala na konkurentosposobnost' regionov [Impact of human capital on regional competitiveness]. Theoretical and Practical Aspects of Economics and Intellectual Property, vypusk 1, T. 1.: 211-215.

11.Fillipova I.A. 2011. Vliyanie razvitiya regiona na formirovanie chelovecheskogo kapitala. Regional'naya ekonomika: teoriya i praktika, 39(219): 9-15.

12. Ushvitskiy L.I., Parakhina V.N. 2005. Konkurentosposobnost' regiona kak novaya realiya: sushchnost', metody otsenki, sovremennoe sostoyanie. Sbornik nauchnykh trudov SevKavGTU. Seriya «Ekonomika», 1: 1-20.

13.Shekhovtseva L.S. 2007. Integral'naya otsenka strategicheskoy konkurentosposobnosti rossiyskikh regionov. Vestnik INZhEKONa, 4 (17):109-115.

14.Stryabkova E.A., Chistnikova I.V., Lyshchikova J.V., Dobrodomova T.N., Mochalova Ya.V., Izvarin A.A. 2018. Human capital as a strategic factor in the development of the regional economy. Revista Publicando, 15: 1492-1502. Mode of access: https://rmlconsultores.com/revista/index.php/crv/article/view/ 1468/pdf_1074

15.Stryabkova E.A., Glotova A.S., Titova I.N., Lyshchikova J.V., Chistnikova I.V. 2018. Modeling and forecasting of socio-economic development of the region. The Journal of Social Sciences Research, 5: 404-410. Mode of access: https://arpgweb.com/pdf-files/spi5.11.404.410.pdf

\section{Ссылка для цитирования статьи For citation}

Глотова А.С., Глотов Д.С., Титова И.Н. 2020. Диагностика конкурентоспособности региона в контексте привлечения человеческого капитала. Экономика. Информатика. 47 (2): 244-253. DOI: 10.18413/2687-0932-2020-47-2-244-253.

Glotova A.S., Glotov D.S., Titova I.N. 2020. Diagnostics of regional competitiveness in the context of attracting human capital. Economics. Information technologies. 47 (2): 244-253 (in Russian). DOI: 10.18413/2687-0932-2020-47-2-244-253. 